\title{
Schule und Corona: Unterricht aussetzen und nur zu Hause aussitzen, ist ein Leerplan
}

In pro \& contra sammeln und veröffentlichen wir Ihre Meinung, Ihre Kritik, Ihre Anregungen, Ihre Fragen!

Als Beispiel haben wir einen Leserbrief von Erwin Rauscher ausgewählt, der sich auf den Gastkommentar von Stefan T. Hopmann „Schule und Corona: Das Leben ist wichtiger als der Lehrplan" bezogen hat. Jener Leserbrief, hier in der Originalfassung nachzulesen, ist in der FURCHE Nr. 14 vom 2. April 2020 (Seite 16) stark verkürzt erschienen.

Nicht nur in Krisen ist das Kindeswohl oberste Pflicht: Fernlehre muss aktuell den normalen Schulbetrieb ersetzen. Wer sie mit Tests und Matura plant, handelt sozial gerecht und pädagogisch verantwortlich.

Den gegenwärtig immensen Bemühungen von Lernenden und Anstiftungen von Lehrenden, allen voran dem Bildungsminister "Hurra-Optimismus“ zu unterstellen, ist Hoppla-Demagogie von Expert*innen, die von der Schule leben wollen, indem sie sich inszenieren und in ihrer Kompetenz sonnen. Die Schule aber braucht Insider*innen, die für die Schule leben, indem sie sich einbringen.

(1) Online-Materialien anzubieten, (2) Fernlehre-Nachteilen vorzubeugen und (3) faire Prüfungsvorbereitung zu gewähren, ist No-na-net-Rhetorik und für Insider*innen Schnee von gestern. Pauschal den Schüler*innen „traumatisierende Erfahrungen“ zu unterstellen, ist viruskonforme Angstmacherei; leistungsanstiftende Fernlehre gegensätzlich zum Kindeswohl zu propagieren, ist Fernleere.

Wie apokalyptisch die täglichen Meldungen zur aktuellen globalen Herausforderung sind, zeigt sich nicht nur in den pandemischen (Re)Aktionen der Gesellschaft, sondern auch in den vielen Sorgen und Ängsten im Inneren der Familien. Davon bleiben Schule und ihr Bildungsauftrag nicht unbeteiligt: Wenn die Rollbalken der Schule heruntergezogen und durch Monitore ersetzt werden, gilt: Wer ohne zu surfen denkt, bleibt allein. Und wer ohne zu denken surft, bleibt zurück. Handy, iPad und Notebook sind über Nacht vom Spielzeug zum Unterrichtsmedium geworden. Längst nicht alles läuft perfekt: Die erste Fernlehre-Woche über erklang Schülerjammern: „So viele Arbeitsaufgaben“, während der zweiten tönt als Lehrerecho: „So viel Korrekturlesen“. Und doch wurden noch nie so wenige Hausübungen abgeschrieben wie jetzt. Solidarität als Zusammenhalten durch Getrennt-Lernen ist zum pädagogischen Antrieb der Stunde geworden: Schüler*innen helfen den Alten; Lehrer*innen 
unterstützen einander; Buchverlage, Kultureinrichtungen, Plattformen aller Art, Rundfunk und Fernsehen überbieten sich mit angebotenen Unterrichtsmaterialien so sehr, dass Lernen über Nacht vom Sammeln zum Auswählen geworden ist und es didaktische Hilfen für zu Hause braucht wie etwa lernentrotzcorona.at u.v.a.

Hausübungen auf dem Schulweg abzuschreiben wird durch Recherche zuhause ersetzt; eigene Leistung zu erbringen ist so selbstverständlich geworden, dass die Schüler*innen der Abschlussklassen ihr Recht auf die Matura einfordern. Nachbarschaftshilfe und Leih-PCs der Schulen sind erste Folgen. Schule als virtueller Begegnungsort braucht Vorbilder, Bessermacher, Menschen, die nicht an ihr verdienen und sich selbst profilieren wollen, sondern solche, die ihr ein neues Profil zuweisen - digitale Bildung statt bloßer Digitalisierung, durch Transfer und Feedback, Dialog in Wertschätzung der personalen Würde ihrer Protagonist*innen. Wissen aus der Forschung wird zum Dienen für die Praxis, nicht umgekehrt.

Hurra den Schüler*innen und Lehrer*innen samt 180-Grad-Wende ihrer Methoden und Beibehalten ihrer Ziele. Dankenswerterweise wird der zuständige Minister nicht müde, reale Rahmenbedingungen für virtuelle Begegnungen zu schaffen und kontinuierlich anzupassen: Distance Learning als Ergänzungsunterricht und Lerncoaching. In Robert Musils „Mann ohne Eigenschaften“ nimmt Ulrich „Urlaub vom Leben“, um in einem Experiment die Zukunft zu erkunden, und vereinsamt. Fernlehre braucht dagegen Sören Kierkegaards Gedanken, dass unser Leben „rückwärts verstanden werden“, aber „vorwärts gelebt werden“ soll: "Just do it" und "Yes, we can“. Als bei Astrid Lindgren Tommy und Annika besorgt sagen: „Der Sturm wird immer stärker“, antwortet Pippi Langstrumpf: „Das macht nichts. Ich auch.“

Wie können Sie Stellung beziehen zu einem Beitrag in diesem Web-Journal, in einem unserer Web-Dialoge oder zu einem, wo auch immer aktuell diskutiertem Thema in Kontext von Schule?

Wir freuen uns auf Ihre Leserbriefe an redaktion@schule-verantworten.at. 